\title{
Toward a Design for Flowable and Extensible lonomers: An Example of Diamine-Neutralized Entangled Poly(styrene-co-4-vinylbenzoic acid) lonomer Melts
}

\author{
Wendi Wang, Jeppe Madsen, Natalja Genina, Ole Hassager, Anne L. Skov,* and Qian Huang* \\ Cite This: Macromolecules 2021, 54, 2306-2315 \\ Read Online
}

ACCESS | Lلll Metrics \& More | 国 Article Recommendations | st Supporting Information

ABSTRACT: Processing ionomers is complicated by their ability to exhibit brittle fracture even in the melt state. This work introduces a new strategy for providing ionomers with good flowability, extensibility, and superior strain hardening. Diamineneutralized entangled poly(styrene-co-4-vinylbenzoic acid) ionomers were studied using small-amplitude oscillatory shear and nonlinear uniaxial extension measurements. The parent molecule, poly(styrene-co-4-vinylbenzoic acid), has a molar mass of 85,400 $\mathrm{g} / \mathrm{mol}$, well above the entanglement molar mass of polystyrene $(13,300 \mathrm{~g} / \mathrm{mol})$. Neutralization was performed using "Jeffamine" type diamines with different molar masses. The resulting neutralized ionomers presented relaxation processes similar to entangled polymers but with faster terminal relaxation, suggesting negligible ionic cluster formation and indicating a diluting effect of the introduced diamines. This feature provides the ionomers with good flowability and facilitates their processing. In extensional measurements, these ionomers displayed superior strain hardening

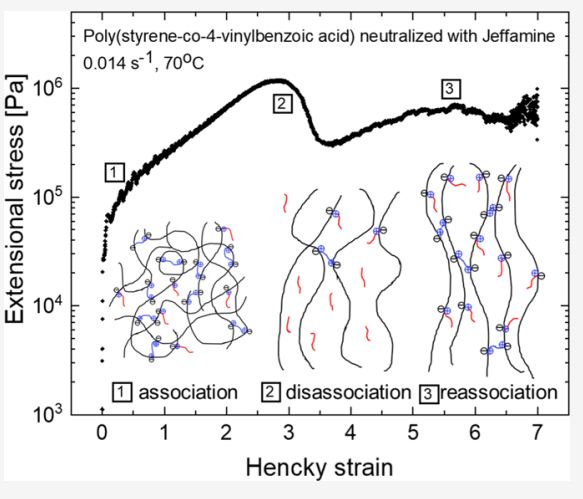
compared to the parent molecule, which also proved to be adjustable via changing

diamine length. The stress growth curves showed a maximum stress, followed by stress overshoot and steady state at larger strain. The stress maximum and overshoot were correlated with ionic sticker disassociation, as evidenced by phase separation-induced color change during filament stretching. At high stretch rates, the stickers disassociate abruptly to accommodate the strain, so that the sticker disassociation time decreased with increasing stretch rates. Good extensibility (up to Hencky strain 7) was achieved via ionic sticker reassociation and entanglements.

\section{INTRODUCTION}

Ionomers are a class of polymers with a small number of bonded ionic species attached to a relatively nonpolar backbone. ${ }^{1}$ They have been used in a variety of applications such as membranes, packaging and films, compatibilizers, shape memory materials, and self-healing materials. ${ }^{1,2}$ Most previously studied ionomers are polysulfonic or carboxylic acids neutralized by metal or ammonium counterions. However, depending on the ion concentration, ${ }^{3,4}$ counterion species, ${ }^{3-6}$ and degree of neutralization, ${ }^{7,8}$ their structure and rheological properties vary significantly.

A distinctive feature of ionomers is the formation of ionic clusters by ion-dipole interactions, which act as physical crosslinks inside the material. This behavior has been confirmed via dynamic mechanical analyses, which showed the presence of a pseudo-rubbery plateau above the glass transition temperature $\left(T_{\mathrm{g}}\right)$, as well as a second mechanical loss process at an elevated temperature. ${ }^{9-11}$ The persistence of ionic clusters gives ionomer melts a higher viscosity and longer relaxation time than their nonionic parent polymer, even though melt fluidity is enabled by "ion hopping": that is, ion pairs hopping from one cluster to another. ${ }^{12-14}$ As a consequence, ionomers are generally difficult to process even at high temperatures. For example, the polyether-estersulfonate copolymer ionomer melts investigated by Shabbir et al. exhibited brittle fracture at Hencky strain below unity at fast extension. ${ }^{15,16}$

Compared to the extensive research on the linear viscoelastic (LVE) behaviors of ionomers, ${ }^{9,17-19}$ their nonlinear viscoelastic properties have received much less attention. Nevertheless, ionomers exhibit fascinating properties in both nonlinear shear and extensional rheology. Unlike highly entangled macromolecules, which exhibit a spectrum of relaxation times, ionomers react rapidly upon large shear deformation and heal quickly due to ionic interactions, even though the backbone of the ionomer has a molar mass well below the entanglement molecular weight. ${ }^{12}$ Shear thickening behavior has been observed for both ionomer solutions and melts ${ }^{20-23}$ and has been attributed to increased inter-chain

Received: October 23, 2020

Revised: January 16, 2021

Published: February 16, 2021 
associations at the expense of intra-chain associations. Ionomers also exhibit quite different extensional rheology properties compared to entangled macromolecules. For example, Ling et al. ${ }^{13}$ reported an increasing modulus with strain rate for alkali metal-neutralized sulfonated oligostyrene ionomer melts; they also observed a maximum stress at low Hencky strain, which they attributed to a catastrophic failure of the physical ionic network. Shabbir et al. ${ }^{15}$ reported a decreasing strain hardening trend with increasing extension rates for poly(tetramethylene glycol) and poly(ethylene oxide) copolymer ionomers. The presence of high solvating poly(ethylene oxide) enabled the ionic groups to move freely to adjust chain conformation, thereby adding ductility to the brittle ionomer. In a more recent study, Wu et al. reported a systematic method for improving ionomer ductility, ${ }^{24}$ attributing high stretchability to a strain-induced reorganization of the ionic stickers, which they termed "pseudo-yielding".

However, because it is difficult to separate relaxation mechanisms due to chain entanglements and ionic interactions, most extensional rheology ionomer studies focus on unentangled polymer chains. ${ }^{13,15,24}$ Stadler et al. ${ }^{25}$ reported elongational rheology of entangled telechelic polybutadiene with acid end groups neutralized by alkali metal ions and found that strain hardening was related to the cohesive strength of the ionic cluster. They also observed reduced relaxation time, likely due to the break-up of ionic clusters during extensional deformation. The relation between chain entanglements and ionic interactions during relaxation remains unknown.

This work aims to develop a strategy for designing ionomers with good flowability, extensibility, and superior strain hardening by studying the relaxation mechanisms of entangled ionomer melts under elongational flow. To achieve good flowability, it is vital to shorten the relaxation time by avoiding the formation of ionic clusters. Two main factors can be adjusted for this purpose when preparing ionomers: (i) ion concentration: for polystyrene (PS)-based ionomers containing sulfonated or carboxylated ionic units, no ionic clusters are detected below ca. $6 \mathrm{~mol} \%$ ion content. ${ }^{10,26}$ In addition, carboxylated ionomers tend to exhibit weaker intermolecular interactions compared to sulfonated ionomers with the same backbone; ${ }^{23,27}$ (ii) counterion species: ammonium can be used as an alternative to metal ions, and the strength of ammonium ionic interactions can be tuned via the molar mass of the amines used. ${ }^{5}$ Strain hardening manifests as higher stress above the corresponding LVE envelope. Ionic interaction leads to superior strain hardening compared to the nonionic parent polymer. Extensibility signifies how much the material can be stretched without fracture. $^{28}$ Enhanced extensibility is ultimately ensured by the double-dynamic network which consists of ionic interactions and chain entanglements, enabling network stretching to continue even after the ionic bonds have been broken. ${ }^{25}$

In this study, entangled poly(styrene-co-4-vinylbenzoic acid) with $5 \mathrm{~mol} \%$ acid was neutralized using diamines of different molar mass. The diamines used were Jeffamines, which are PEO-PPO copolymers. Compared to random sulfonated ionomers, ${ }^{29}$ the ionic interactions in our system tended to distribute homogeneously along the polymer backbone. Using longer-chain ammonium as a counterion prevented ionic cluster formation, resulting in reduced relaxation time and facilitating ionomer processing. The LVE behavior and nonlinear extensional behavior of the ionomer were studied, and the relaxation mechanism under extensional flow was elucidated.

\section{EXPERIMENTAL SECTION}

Materials. Diamine series Jeffamine ED600, ED900, and D2000 were purchased from Huntsman and used as received. Their molar mass and composition can be found in the Supporting Information. PS was prepared using a bifunctional naphthyllithium initiator in accordance with the literature. ${ }^{30,31}$ Styrene oligomer was bought from Sigma-Aldrich. The molar mass and dispersity of all materials were measured, and the results are listed in Table 2.

Table 1. Sample Compositions for Two PS Solutions

\begin{tabular}{ccccc} 
sample & constituent 1 & $w_{1} \%$ & constituent 2 & $w_{2} \%$ \\
PS77kOS2k-68 & PS77k & 68 & OS2k & 32 \\
PS77kOS2k-82 & PS77k & 82 & OS2k & 18 \\
\hline
\end{tabular}

Poly(styrene-co-4-vinylbenzoic acid) (PS-co-PVBA) with $5 \mathrm{~mol} \%$ 4-vinylbenzoic acid was synthesized according to the methods described in our previous work. ${ }^{32}$ The resulting weight-averaged molar mass $M_{\mathrm{w}}$ is $85,400 \mathrm{~g} / \mathrm{mol}$, corresponding to 6.4 entanglements per chain (entanglement molecular weight, $M_{\mathrm{e}}=13.3 \mathrm{~kg} / \mathrm{mol}^{33}$ ).

Neutralization. About $2 \mathrm{~g}$ of poly(styrene-co-4-vinylbenzoic acid) was first dissolved in tetrahydrofuran (THF); Jeffamine ED600, ED900, and D2000 were then added in parallel at a stoichiometric ratio of the two functional species: for example, amine and carboxylic acid. Detailed quantities are listed in the Supporting Information. The mixture was rotated on a set of rollers for $1 \mathrm{~h}$ to ensure full reaction. The resulting viscous solution was transferred to a polypropylene vial and allowed to evaporate in a fume hood overnight. Finally, the polymer film was placed in a vacuum oven at $70^{\circ} \mathrm{C}$ for $24 \mathrm{~h}$.

Preparation of PS Solution. Two PS solutions were prepared as control samples with the following compositions (see Table 1): PS77kOS2k-68 was prepared by solvent evaporation, while PS77kOS2k-82 was prepared by precipitation as described in ref 34 . The concentrations of both PS solutions were determined by integrating the peak areas of the bimodal curve using size exclusion chromatography (SEC).

Nuclear Magnetic Resonance Analysis. Nuclear magnetic resonance spectroscopy was performed on a Bruker $300 \mathrm{MHz}$ spectrometer. Jeffamine (60 mg; ED600, ED900, or D2000) was dissolved in $0.6 \mathrm{~mL}$ of $\mathrm{CDCl}_{3}$. After acquisition of spectra, $0.05 \mathrm{~mL}$ of trifluoroacetic acid was added to each sample, and the spectra of the protonated samples were acquired immediately after. All spectra were acquired using 128 scans.

Size Exclusion Chromatography. SEC was carried out on a chromatographic system consisting of a Viscotek VE 2001 GPC solvent/sample module connected to a Viscotek TriSEC model 302 triple detector array (RI, light scattering, viscometer). The columns were a PL Guard and two PL gel mixed D columns from Polymer Laboratories, connected in series; this column combination provides good resolution up to $300,000 \mathrm{Da}$ and was calibrated with narrow molar mass polystyrene standards (PSS, Mainz, Germany). All samples and calibration standards were analyzed using a flow rate of $1 \mathrm{~mL} / \mathrm{min}$. Sample solutions were made up to $5 \mathrm{mg} / \mathrm{mL}$ in THF; when needed, another $10 \mu \mathrm{L}$ of acetic acid was added to suppress interactions. Toluene was used as an internal flow rate marker.

Fourier Transform Infrared Spectroscopy Analysis. Fourier transform infrared (FTIR) spectroscopy was carried out using a Nicolet iS50 FTIR spectrometer (Thermo Fisher Scientific, USA). The wavenumber between 400 and $4000 \mathrm{~cm}^{-1}$ was recorded for each sample in either transmission mode or attenuated total reflection mode.

Differential Scanning Calorimetry. Differential scanning calorimetry (DSC) measurements were performed on a Discovery DSC (TA Instruments, USA) in a nitrogen atmosphere with a heating and cooling rate of $10{ }^{\circ} \mathrm{C} \mathrm{min}{ }^{-1}$. The tested samples weighed around 2-5 mg. All samples were heated well above the glass transition 
Table 2. Data for Materials Used in This Study: Parent Polymer, Neutralized Ionomers, Jeffamines, and Control Samples

\begin{tabular}{|c|c|c|c|c|}
\hline material & $M_{\mathrm{w}}(\mathrm{SEC})[\mathrm{g} / \mathrm{mol}]$ & $M_{\mathrm{w}} / M_{\mathrm{n}}(\mathrm{SEC})$ & $T_{\mathrm{g}}\left[{ }^{\circ} \mathrm{C}\right]^{b}$ & remark \\
\hline $\mathrm{PS}_{0.95} \mathrm{~A}_{0.05}$ & 85,400 & 1.22 & 105 & parent polymer \\
\hline $\mathrm{PS}_{0.95} \mathrm{~A}_{0.05}+\mathrm{ED} 600$ & $81,100^{a}$ & 1.27 & 76 & ionomer under investigation \\
\hline $\mathrm{PS}_{0.95} \mathrm{~A}_{0.05}+\mathrm{ED} 900$ & $87,700^{a}$ & 1.18 & 66 & ionomer under investigation \\
\hline $\mathrm{PS}_{0.95} \mathrm{~A}_{0.05}+\mathrm{D} 2000$ & $85,000^{a}$ & 1.27 & 25 & ionomer under investigation \\
\hline Jeffamine ED600 & 656 & 1.08 & & ionomer component \\
\hline Jeffamine ED900 & 940 & 1.22 & & ionomer component \\
\hline Jeffamine D2000 & 2144 & 1.18 & -70 & ionomer component \\
\hline PS77k & 77,000 & 1.10 & & control sample component \\
\hline OS2k & 1900 & 1.10 & & control sample component \\
\hline PS77kD2000 blend & $77,000 / 2144$ & $1.10 / 1.18$ & $-67 / 81$ & control sample \\
\hline PS77kOS2k-68 & $77,000 / 1900$ & $1.10 / 1.10$ & 87 & control sample \\
\hline PS77kOS2k-82 & $77,000 / 1900$ & $1.10 / 1.10$ & 97 & control sample \\
\hline
\end{tabular}

${ }^{a}$ The neutralized ionomers show nonmonotonous change in $M_{\mathrm{w}}$ and dispersity; the actual normalized chromatograms are added to show the small instrumental variation, as can be seen in Figure S4. ${ }^{b}$ For Jeffamines, the glass transition temperature is only measured for sample D2000 in order to identify the PS77kD2000 blend composition on DSC.

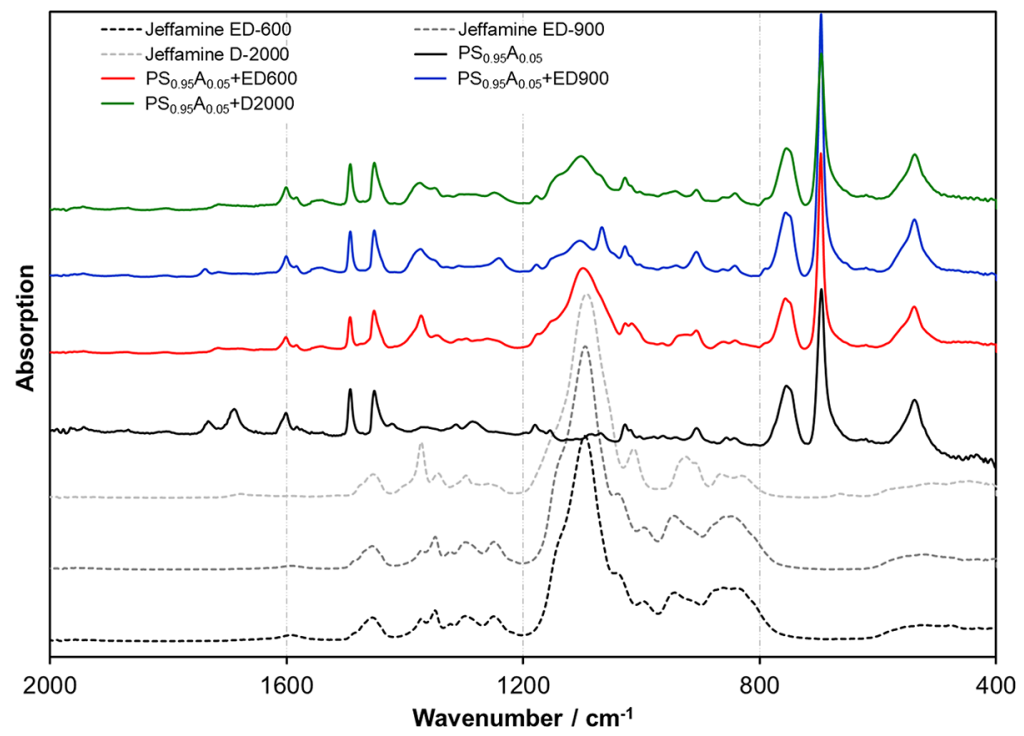

Figure 1. IR absorption spectra from 400 to $2000 \mathrm{~cm}^{-1}$ for neutralized ionomers, parent polymer, and Jeffamines (spectra from 400 to $4000 \mathrm{~cm}^{-1}$ are available in the Supporting Information).

temperature to eliminate sample history, cooled, and finally heated to $200{ }^{\circ} \mathrm{C}$. Glass transition temperatures $\left(T_{\mathrm{g}}\right)$ were determined from the second heating curve.

Mechanical Spectroscopy. The LVE properties of the polymer melts were obtained from small-amplitude oscillatory shear measurements. An $8 \mathrm{~mm}$ plate-plate geometry was used on an ARES-G2 rheometer (TA Instruments). Measurements were performed at temperatures between $T_{\mathrm{g}}+25{ }^{\circ} \mathrm{C}$ and $T_{\mathrm{g}}+65{ }^{\circ} \mathrm{C}$ under nitrogen protection. For each sample, the data were shifted to build a master curve at reference temperature $T_{\text {ref }}$.

Extensional Stress Measurement. Nonlinear rheological behavior in extensional flow was studied above $T_{\mathrm{g}}$ using a filament stretching rheometer (VADER, Rheo Filament ApS) under constant strain rate, $\dot{\varepsilon}$, where both normal force, $F(t)$, and diameter evolution, $2 R(t)$, were measured. Prior to measuring, all samples were molded into cylindrical specimens with a fixed radius, $R_{0}(2.7 \mathrm{~mm})$. The initial sample length, $L_{0}$, was controlled by sample amount, yielding an aspect ratio $\left(\Delta_{0}=L_{0} / R_{0}\right)$ of around 0.5 . All tests were carried out at $T_{\text {ref }}$ under nitrogen protection.

The Hencky strain of the mid-filament plane is calculated as

$$
\varepsilon_{\mathrm{H}}(t)=-2 \ln \left(R(t) / R_{0}\right)
$$

With a small aspect ratio, an extra shear contribution may add to the measured extensional force during the start-up flow due to the noslip condition at the two ends of a filament. The corrected stress, with respect to this shear component in the extensional flow, is calculated $\mathrm{as}^{35}$

$$
\begin{aligned}
\left\langle\sigma_{z z}-\sigma_{r r}\right\rangle= & \frac{F(t)-\frac{m g}{2}}{\pi R(t)^{2}} \\
& \times \frac{1}{1+\left(R(t) / R_{0}\right)^{10 / 3} \exp \left(-\Delta_{0}^{3}\right) /\left(3 \Delta_{0}^{2}\right)}
\end{aligned}
$$

where $m$ is the sample weight and $g$ is the gravity constant.

The extensional stress growth coefficient is defined as $\eta^{+}=\left\langle\sigma_{z z}-\right.$ $\left.\sigma_{r r}\right\rangle / \dot{\varepsilon}$.

\section{RESULTS AND DISCUSSION}

Neutralization. The resulting synthesized ionomers were transparent and were checked by FTIR spectroscopy. Figure 1 shows that the carbonyl stretch around $1700 \mathrm{~cm}^{-1}$ (unimer and dimer of carboxylic acid) almost disappears upon addition of Jeffamine. Jeffamine bonds are also clearly seen in the ionomers around $1100 \mathrm{~cm}^{-1}$. The molar mass and dispersity of 

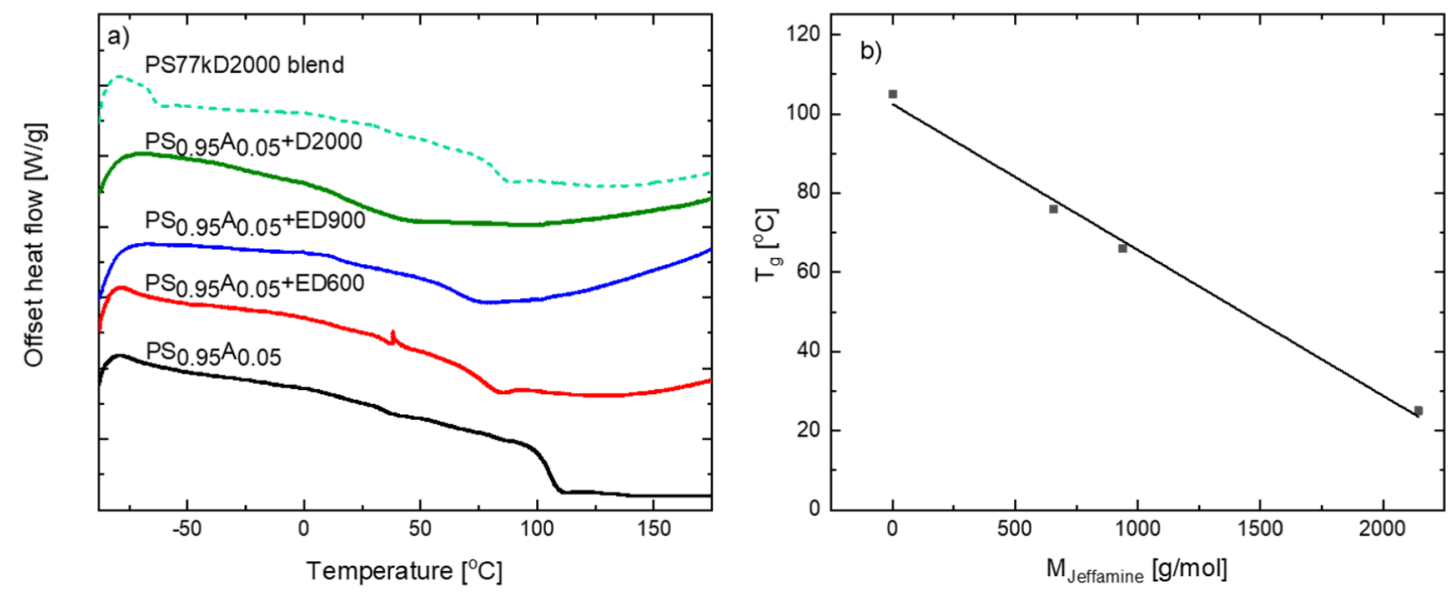

Figure 2. (a) DSC traces: second heating cycle used to assess $T_{\mathrm{g}}$, heat $/$ cool rate: $10{ }^{\circ} \mathrm{C} / \mathrm{min} ;(\mathrm{b}) T_{\mathrm{g}}$ as a function of Jeffamine molar mass $[$ the black line represents linear fitting $\left.\left(R^{2}=0.99\right)\right]$.
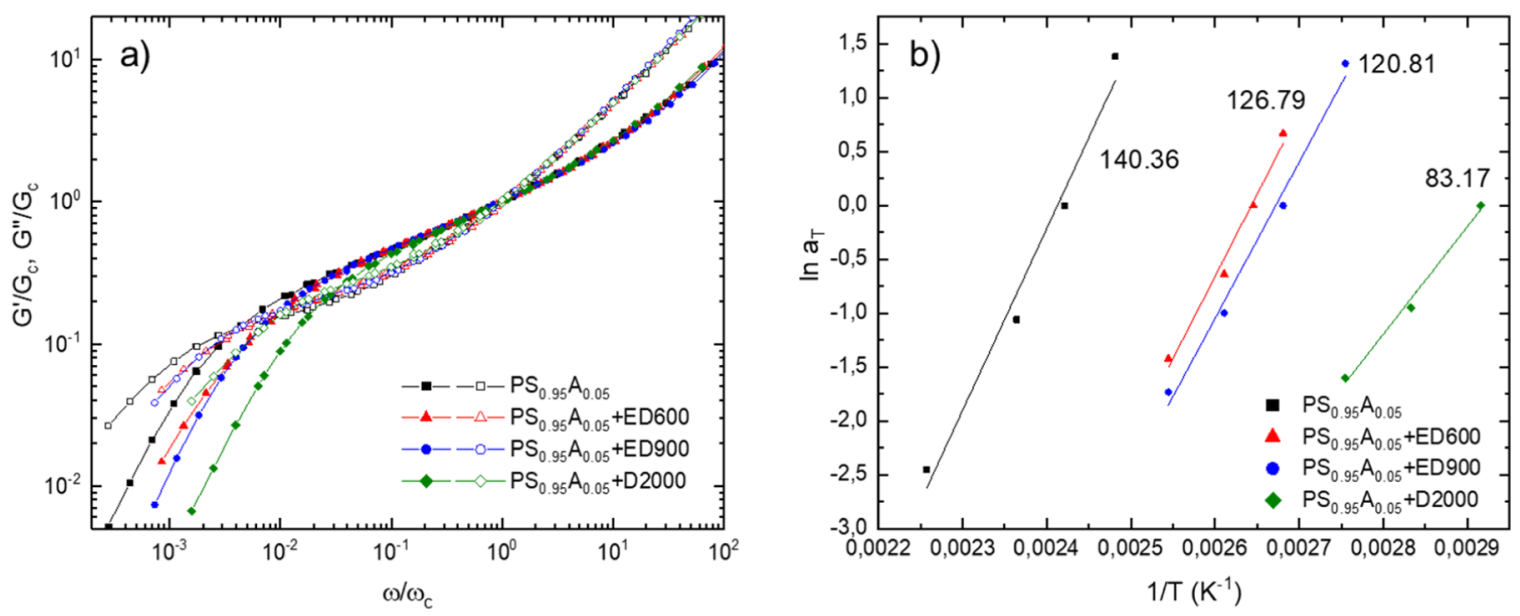

Figure 3. (a) LVE data after normalization to the modulus and angular frequency at the high-frequency crossover point (closed symbols for $G^{\prime}$, open symbols for $G^{\prime \prime}$; the solid lines are drawn to guide the eyes). (b) Fitting of shift factor $a_{\mathrm{T}}$ to the Arrhenius equation; the activation energy is indicated in the figure as $\mathrm{kJ} / \mathrm{mol}$.

the resulting diamine-neutralized poly(styrene-co-4-vinylbenzoic acid) are listed in Table 2.

Thermal Properties. The DSC traces in Figure 2a indicate that incorporating Jeffamine produces a decrease in $T_{\mathrm{g}}$ with increasing Jeffamine length and that the transition seems to broaden. The diamine chains behave as an internal plasticizer, and the $T_{\mathrm{g}}$ decreases linearly as the molar mass of Jeffamine increases (see Figure 2b). A similar decrease in $T_{\mathrm{g}}$ has also been observed for flexible diamine-modified epoxy resins, ${ }^{36}$ ammonium-neutralized sulfonated PS ionomers, ${ }^{5}$ and polyester-sulfonate ionomers with ionic liquid counterions, ${ }^{37}$ potentially related to weaker ion-dipole interactions and an increase in chain mobility. The $T_{\mathrm{g}}$ values for this series of neutralized ionomers are also summarized in Table 2. It is noted that some changes of the ionomers may occur at high temperature (the upturn of DSC traces at high temperature in Figures 2 and S5), so the temperature is deliberately kept low for rheological measurements, and the phenomenon is not further investigated as it is outside the scope of this work.

Importantly, only a single glass transition is observed for ionomers, suggesting that the synthesized materials are homogeneous; moreover, due to ionic interaction, phase separation is not detected. ${ }^{38-40}$ A previous study by Weiss et al. ${ }^{39}$ also confirms that the miscibility of PS and poly(alkylene oxide) blends is enhanced by specific intermolecular interactions between amine and sulfonic acid, while a study by Yang and Han. ${ }^{41}$ demonstrated that two polymers with specific interactions are miscible, even though the difference in component glass transition temperature $\left(\Delta T_{\mathrm{g}}\right)$ between blends can be as large as $199{ }^{\circ} \mathrm{C}$. A control sample consisting of a simple blend of PS $77 \mathrm{~kg} / \mathrm{mol}$ and Jeffamine D2000 appears white and displays two glass transitions in the DSC curve, as shown by the green dashed line in Figure 2a, suggesting the phase separation that was not observed in the ionomers.

Linear Rheology. Figure 3a shows the storage modulus, $G^{\prime}$, and loss modulus, $G^{\prime \prime}$, of these materials as a function of angular frequency, $\omega$. For each sample, both frequency and modulus are normalized by the second crossover point $\left(\omega_{c}\right.$ and $G_{\mathrm{c}}$ ) in order to compensate for the $T_{\mathrm{g}}$ difference (nonnormalized master curves are available in the Supporting Information, Figure S7). The Rouse relaxation time of the parent polymer is $8.25 \mathrm{~s}$ and is calculated as $\tau_{\mathrm{R}}=Z^{2} \tau_{\mathrm{c}}$ (where $Z$ is the number of entanglements per chain calculated by $M / M_{\mathrm{e}}$ and $\tau_{\mathrm{c}}$ is the relaxation time of one entangled strand, estimated as $1 / \omega_{c}$; the entanglement molar mass of pure PS $\left(M_{e}=13.3\right.$ $\mathrm{kg} / \mathrm{mol}$ ) is used for the parent polymer since hydrogen bonding is demonstrated not to be active at high temperature $\left.^{32}\right)$. Similar to their parent polymer, all ionomer melts 

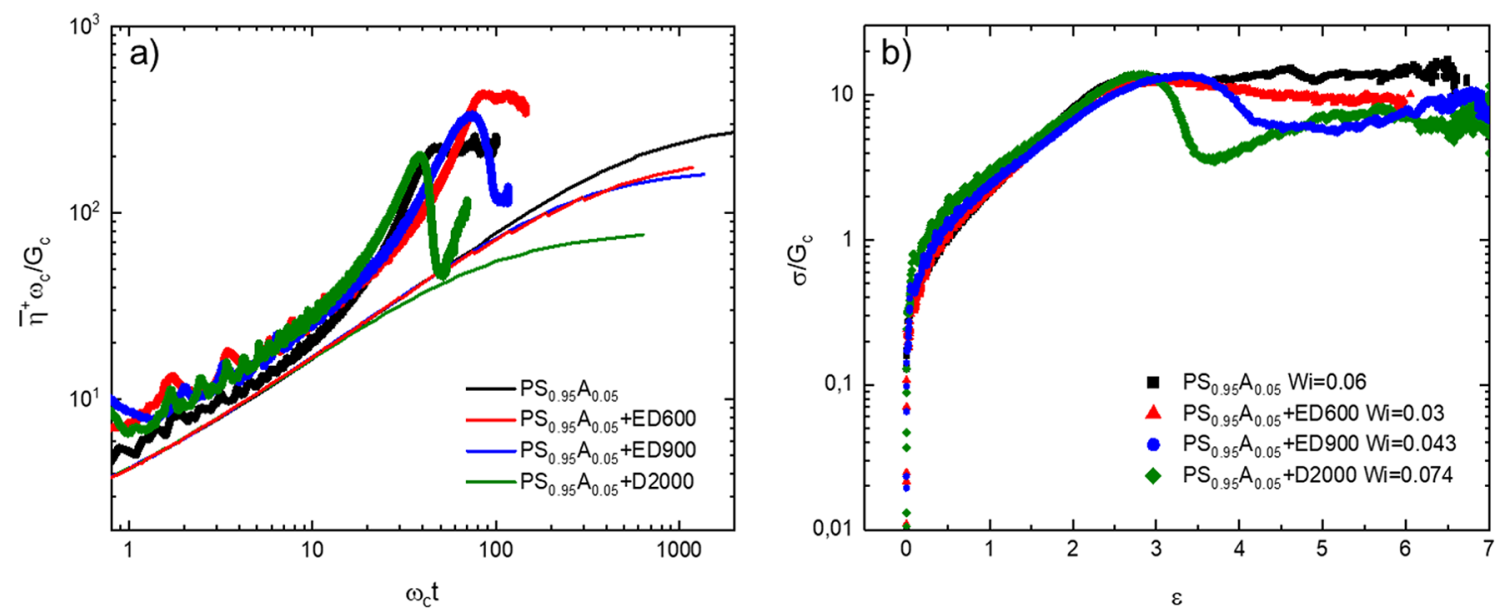

Figure 4. Comparison of normalized extensional behavior across all the four samples: (a) normalized extensional stress growth coefficient as a function of time; (b) normalized stress as a function of Hencky strain. The strain rate for $\mathrm{PS}_{0.95} \mathrm{~A}_{0.05}$ at $140{ }^{\circ} \mathrm{C}$ is $0.3 \mathrm{~s}^{-1}$; the strain rate for $\mathrm{PS}_{0.95} \mathrm{~A}_{0.05}+\mathrm{ED} 600$ at $105{ }^{\circ} \mathrm{C}$ is $0.085 \mathrm{~s}^{-1}$; the strain rate for $\mathrm{PS}_{0.95} \mathrm{~A}_{0.05}+\mathrm{ED} 900$ at $100{ }^{\circ} \mathrm{C}$ is $0.109 \mathrm{~s}^{-1}$; and the strain rate for $\mathrm{PS}_{0.95} \mathrm{~A}_{0.05}+\mathrm{D}_{2000}$ at $70^{\circ} \mathrm{C}$ is $0.114 \mathrm{~s}^{-1}$. The corresponding Weissenberg numbers $\left(W i=\dot{\varepsilon} / \omega_{\mathrm{c}}\right)$ are $0.06,0.03,0.043$, and 0.074 , respectively.

display relaxation processes typical of entangled linear polymers. The four normalized curves overlap at high frequency, indicating an identical Rouse relaxation process. At medium and low frequency range, the terminal relaxation time is observed to decrease with increasing diamine length, indicating no/negligible effect of ionic clusters inside the ionomers. Since the ion-dipole interaction becomes weaker by increasing counterion size, chances of forming ionic clusters become less, and the Jeffamine chains also have the plasticizing effect. This finding is in contrast to the sticky Rouse/Reptation dynamics exhibited by unentangled ionomers. ${ }^{15,42,43}$ Furthermore, the diamines show a diluting effect on the long chains, which can be visualized by comparing the activation energy, $E_{a}$ which is obtained by fitting experimental data to the Arrhenius equation $\left(a_{\mathrm{T}}(T)=\exp \left[\frac{E_{\mathrm{a}}}{R}\left(\frac{1}{T}-\frac{1}{T_{0}}\right)\right]\right.$, where $a_{\mathrm{T}}$ is the shift factor, $R$ is the gas constant, and $T$ and $T_{\mathrm{o}}$ are the test and reference absolute temperatures, respectively). Plotting $\ln \left(a_{\mathrm{T}}\right)$ as a function of $1 / T$, it is clear that the activation energy also decreases with increasing Jeffamine length (see Figure $3 b$ ), indicating less flow resistance and thus a faster relaxation; this both significantly facilitates processing and differentiates the materials studied here from entangled random ionomers that usually display either a double plateau of stickers and entanglements or a prolonged terminal relaxation. ${ }^{19,44}$

Nonlinear Rheology. Figure 4 shows the nonlinear extensional behavior of the four studied samples. Sample $\mathrm{PS}_{0.95} \mathrm{~A}_{0.05}$ was stretched faster than the inverse Rouse time, resulting in oriented and stretched polymer chains. The other samples were stretched at a constant stretch rate to match the maximum normalized stress of the parent polymer. Due to the difference in glass transition temperature between samples, it was necessary to measure the nonlinear extensional behavior at different stretch rates at reference temperatures. The data presented here have been normalized by $G_{c}$ and $\omega_{c}$ for comparison. In Figure 4a, all samples display strain hardening behavior, as the normalized stress growth coefficients are well above the LVE envelope. The degree of strain hardening can be compared by strain hardening factor (SHF), which is defined as the ratio of the stress growth coefficient to the respective LVE value (see Figure S10). For these samples having similar normalized stress as can be seen in Figure $4 b$, the SHFs of both samples PS $\mathrm{P}_{0.95} \mathrm{~A}_{0.05}+$ ED600 and PS ${ }_{0.95} \mathrm{~A}_{0.05}$ + ED900 are higher than their parent polymer with a lower $W i$, indicating an effectively stronger strain hardening as a result of ionic interaction. Sample $\mathrm{PS}_{0.95} \mathrm{~A}_{0.05}+\mathrm{D} 2000$ had a similar SHF as sample $\mathrm{PS}_{0.95} \mathrm{~A}_{0.05}+\mathrm{ED} 900$ but higher $W i$, likely due to the strain hardening effect being compromised by the presence of the longest diamine chain, D2000. (Samples $\mathrm{PS}_{0.95} \mathrm{~A}_{0.05}+$ ED900 and $\mathrm{PS}_{0.95} \mathrm{~A}_{0.05}+\mathrm{D} 2000$ are also stretched at the same $\tau_{\mathrm{c}}$ based Weissenberg number as the parent polymer, and the effect of different Jeffamines are clearly seen in Figure S9.) In Figure $4 b$, at a larger strain, the samples containing ionic interaction displayed a stress overshoot, which was found to be repeatable, as demonstrated in Figures S11 and S12. More interestingly, sample $\mathrm{PS}_{0.95} \mathrm{~A}_{0.05}+\mathrm{D} 2000$ exhibits an undershoot after the stress overshoot, which can be related to sticker reassociation (see the discussion below). Finally, all the ionomer melts reached the same steady stress at the Hencky strain close to 6 .

The rest of this section will focus on answering three questions which could help to elucidate what happens during extension: (i) the role of ionic interactions (stickers) in the start-up extensional flow; (ii) the role of stickers at a large strain; and (iii) the influence of stretching on sticker disassociation time.

Role of Ionic Interaction (Stickers) in the Start-up Extensional Flow. As discussed in the linear rheology section above, the diamines have a diluting effect on the long chains PS-co-PVBA. To determine the extent of this dilution, two PS solutions consisting of short and long PSs were prepared (see Table 1): sample PS77kOS2k-68 had the same weight fraction of long chains as sample $\mathrm{PS}_{0.95} \mathrm{~A}_{0.05}+\mathrm{D} 2000$ and served as an extreme sample in which all diamine chains act as solvents; sample PS77kOS2k-82 had a higher weight fraction of long chains and thus a slightly higher number of entanglements than sample PS77kOS2k-68. The normalized LVEs of both PS solutions were compared with $\mathrm{PS}_{0.95} \mathrm{~A}_{0.05}+\mathrm{D} 2000$, as can be seen in Figure S13. Sample PS77kOS2k-68 displayed a faster terminal relaxation than the ionomer, whereas PS77kOS2k-82 had a very similar terminal relaxation with the ionomer. This suggests that the diamine chains are attached to the backbone at equilibrium and that they connect different chains while 


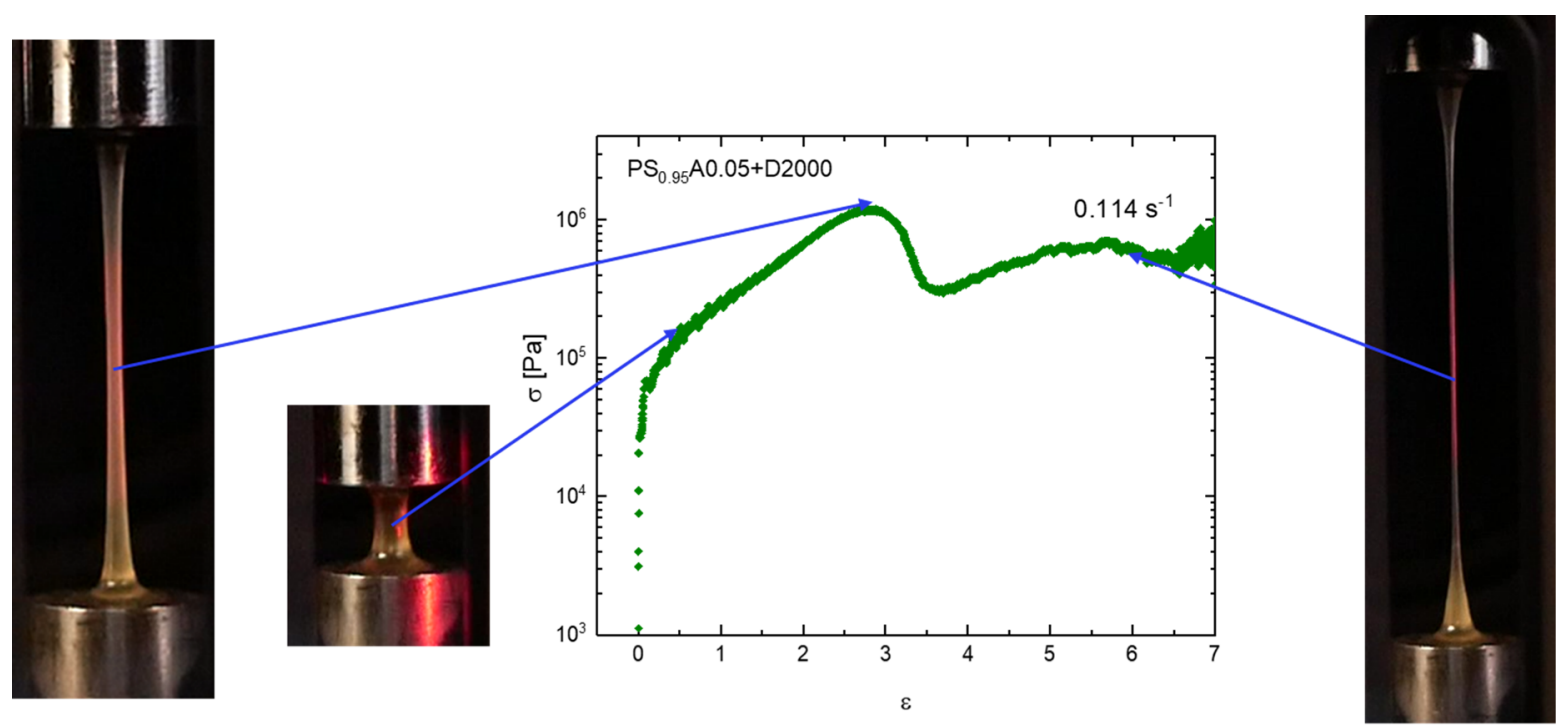

Figure 5. Filament color change during extension measurement of sample $\mathrm{PS}_{0.95} \mathrm{~A}_{0.05}+\mathrm{D} 2000$ stretched at $70{ }^{\circ} \mathrm{C}, 0.114 \mathrm{~s}^{-1}$ : the filament is initially transparent and then gradually turns opaque before becoming transparent again. The color change could be related to the transition from ionic sticker association (left) to disassociation (middle) to reassociation (right).
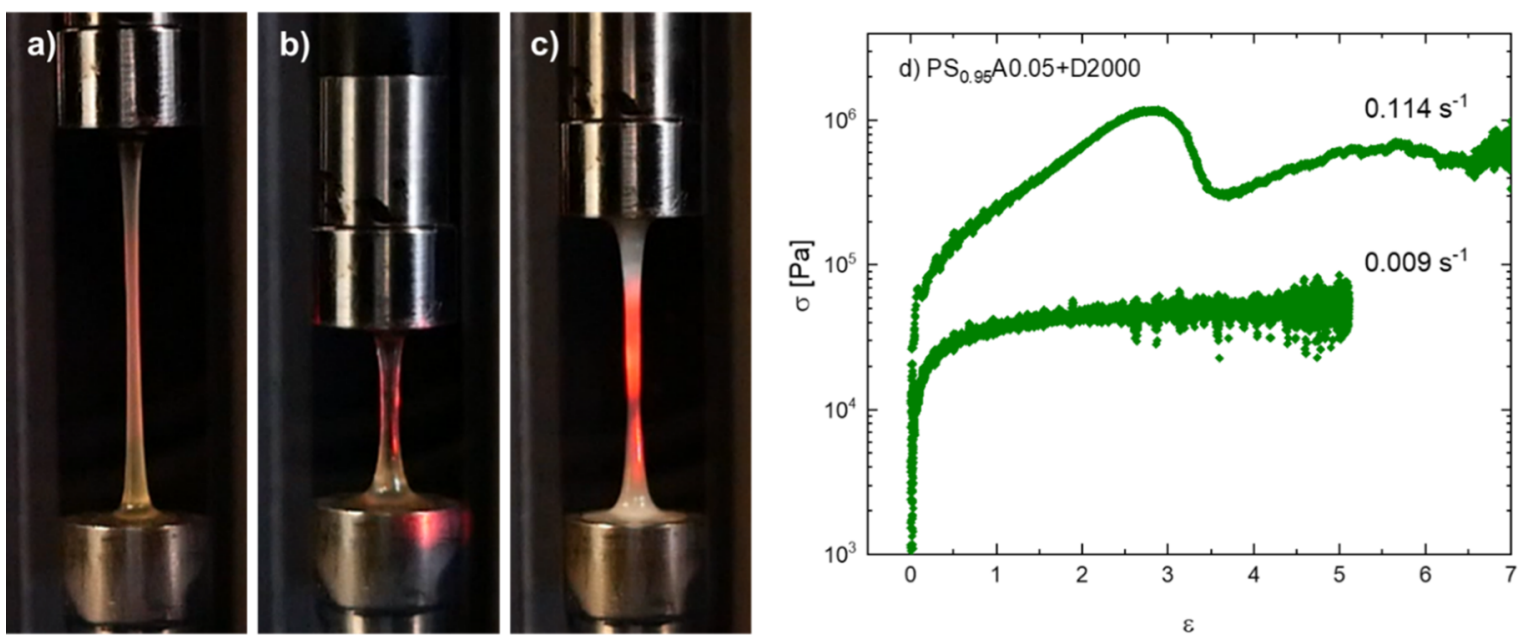

Figure 6. (a-c) Capture of filament stretching at Hencky strain 2.8. (a) $\mathrm{PS}_{0.95} \mathrm{~A}_{0.05}+\mathrm{D} 2000$ stretched at $70{ }^{\circ} \mathrm{C}, 0.114 \mathrm{~s}^{-1}$ (the same as the left photo in Figure 5); (b) $\mathrm{PS}_{0.95} \mathrm{~A}_{0.05}+\mathrm{D} 2000$ stretched at $70{ }^{\circ} \mathrm{C}, 0.009 \mathrm{~s}^{-1}$; (c) PS77kD2000blend stretched at $110^{\circ} \mathrm{C}, 0.114 \mathrm{~s}^{-1}$; and $(\mathrm{d})$ stressstrain response for $\mathrm{PS}_{0.95} \mathrm{~A}_{0.05}+\mathrm{D} 2000$ stretched at $70{ }^{\circ} \mathrm{C}, 0.114 \mathrm{~s}^{-1}$ and $0.009 \mathrm{~s}^{-1}$.

simultaneously keeping them separate from each other (see Figure 8a). The following discussion will focus on sample $\mathrm{PS}_{0.95} \mathrm{~A}_{0.05}+\mathrm{D} 2000$ since Jeffamine D2000 had the most obvious stress overshoot effect among the three neutralized ionomers studied.

At the onset of strong extensional flow (the green curve in Figure 4), the connected diamine chains are stretched together with the backbone. However, when the force reaches a sufficient magnitude, the stickers can start to disassociate. This disassociation is visible as a filament color change during stretching, as can be seen in Figure 5 (recorded videos are also available in the Supporting Information). The melt stretched at $0.114 \mathrm{~s}^{-1}$ and $70{ }^{\circ} \mathrm{C}$ is initially transparent before gradually turning opaque, especially close to maximum stress. For comparison, the same melt was also stretched at a lower rate of $0.009 \mathrm{~s}^{-1}$, for which the stress overshoot is not apparent (see Figure $6 \mathrm{~d}$ ). Figure $6 \mathrm{~b}$ shows a transparent filament stretched at $0.009 \mathrm{~s}^{-1}$ at the same strain as in Figure 6a. Finally, a blend of PS77k and Jeffamine D2000 (control sample) was also stretched and compared with the previous two samples (Figure $6 c)$. The blended filament appeared white throughout the stretching process, indicating a total phase separation of two constituents. While we suggest that the stress maximum and overshoot presented in entangled ionomer melts are related to sticker disassociation and a resulting micro-phase separation, future studies, for example, in situ scattering, may be required to fully understand the underlying physics of the phase separation. Similarly, a maximum stress in extension for alkali metal-neutralized sulfonated oligostyrene ionomer melts is likely associated with chain pull-out from ionic clusters. ${ }^{13}$

Role of Stickers at Large Strain. As can be seen in Figure 5, when sample $\mathrm{PS}_{0.95} \mathrm{~A}_{0.05}+\mathrm{D} 2000$ was stretched at $70{ }^{\circ} \mathrm{C}, 0.114$ $\mathrm{s}^{-1}$, the filament turned from opaque to transparent again at larger Hencky strain, suggesting a reassociation of sticker pairs via ionic interaction. During continued extensional flow, it is easier for a sticker to find a neighbor sticker rather than a remote one. To check this idea, the corresponding PS solution, PS77kOS2k-82, which has overlapping LVE with $\mathrm{PS}_{0.95} \mathrm{~A}_{0.05}+$ 


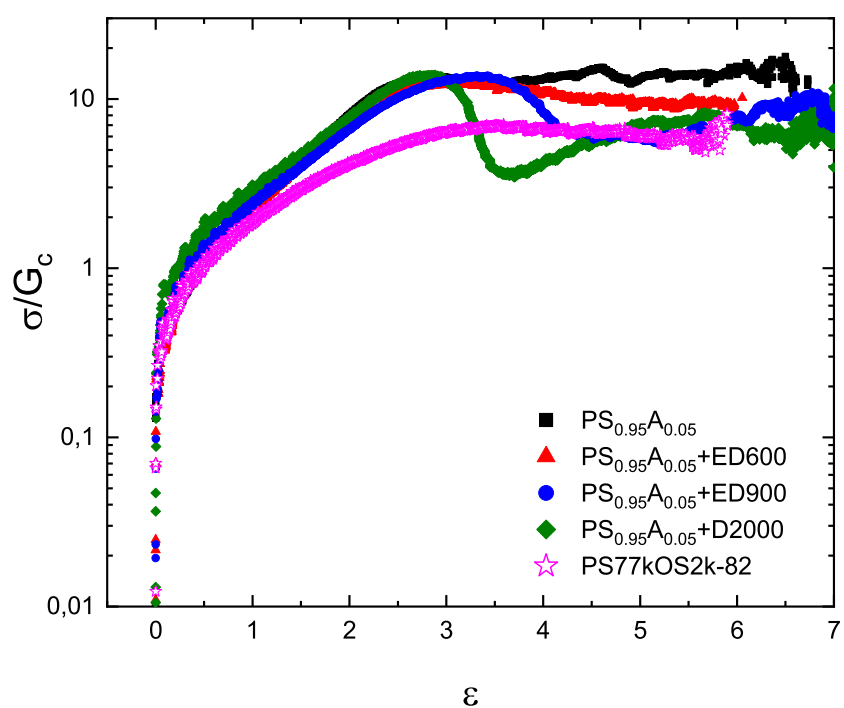

Figure 7. Comparison of normalized stress as a function of Hencky strain for PS solution and ionomers; sample PS77kOS2k-82 is stretched at $120{ }^{\circ} \mathrm{C}, 0.142 \mathrm{~s}^{-1}$. a)

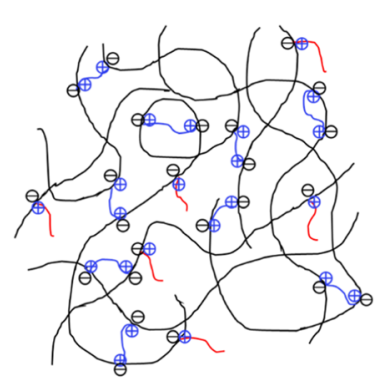

b)

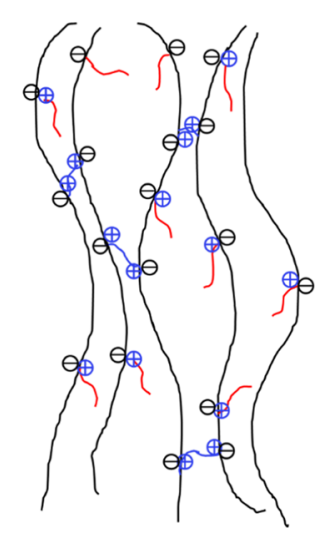

Figure 8. Schematic representations of a diamine-neutralized poly(styrene-co-4-vinylbenzoic acid) ionomer melt: (a) at equilibrium and (b) during extension at large strain.

D2000, was stretched at the same Wi. The normalized stressstrain curves of the two samples are compared in Figure 7: both melts reach the same normalized steady stress around Hencky strain 4.5 (green and pink curves), suggesting reassociation of ionic stickers in the ionomers. Indeed, since these two samples have the same normalized LVEs and steady stress, the stress maximum and overshoot are necessarily related to sticker disassociation. Sticker reassociation can also be confirmed from the reproducible undershoot in stressstrain curves (as can be seen in Figure S11) and stress relaxation test.

In the stress relaxation test, the flow was stopped at Hencky strain 2.8 and kept at the same temperature while maintaining the same deformation at the mid-filament plane. As can be seen in Figure 9, the filament turns from opaque to transparent again, suggesting sticker reassociation and finally a return to equilibrium.

It should also be noted that the ionomers studied display good extensibility due to their double-dynamic network structure: although the stickers dissociate in the strong flow at high rates, the entanglements still continue to contribute to the stress and allow sticker reassociation. While a pure ionomer would exhibit brittle fracture as reported by Shabbir et al. ${ }^{16}$ with the aid of entanglement network, our ionomers have a chance to dissipate energy and thus the fracture can be avoided (see Figure $8 \mathrm{~b}$ ).

Influence of Stretching on Sticker Disassociation Time. To investigate the influence of chain stretching on sticker disassociation time, sample $\mathrm{PS}_{0.95} \mathrm{~A}_{0.05}+\mathrm{D} 2000$ was stretched at different rates, ranging from 0.066 to $0.5 \mathrm{~s}^{-1}$ (see Figure 10a, two lower stretch rates are also included). Both maximum stress and stress overshoot existed for all stretch rates, except for the fastest stretch rate of $0.5 \mathrm{~s}^{-1}$, at which the sample failed during stretching. Note that the stress overshoot and undershoot were observed to be strong for stretch rates faster than $0.2 \mathrm{~s}^{-1}$ as a result of an experimental issue: namely, the online rheometer control engages when there is a small deviation in diameter, as can be seen in Figure S14. As discussed previously, the decrease in stress after reaching its maximum is the result of sticker disassociation. It would therefore be interesting to study different parameters, such as stress, strain, and time, at maximum stress.

The plots in Figure 10b show that maximum stress increases monotonically with strain rate. In Figure 10c, the Hencky strain at which the maximum stress locates $\left(\varepsilon_{\max }\right)$ is plotted as a function of stretch rate. The data falls into two distinct regimes: at low rates, the ionic stickers can exchange pairs prior to the point of massive disassociation such that $\varepsilon_{\max }$ is ratedependent and increases with stretch rate; at higher rates, $\varepsilon_{\max }$ reaches a steady value and becomes relatively independent of stretch rate. It is possible that the fast flow $\left(\dot{\varepsilon}>0.114 \mathrm{~s}^{-1}\right)$ does not allow ion pair reorganization before considerable disassociation, so that the stickers disassociate abruptly to accommodate the strain. Figure $10 \mathrm{~d}$ plots time, $t_{\max }$, where the maximum stress locates as a function of stretch rate. The influence of chain stretching on sticker disassociation time becomes clearer: at low rate, the sticker disassociation time approaches the sticker lifetime from LVE measurement (see the Supporting Information). At higher rates, the sticker network survival becomes dependent on the overall strain, whereby the sticker disassociation time becomes inversely proportional to the rate. To the best of our knowledge, the influence of chain stretching on sticker disassociation time has not been reported previously.

The advantages of the ionomer system proposed here are clear: ionomer melts possess superior strain hardening behaviors at a Weissenberg number lower than the nonionic parent polymer. The proposed system can also bear higher stress compared to solutions with the same LVE and displays high extensibility, with the potential to reach a maximum Hencky strain of 7 due to its double-dynamic network structure of ionic interactions and entanglements. Finally, the neutralized ionomers studied here can be processed at lower temperatures and stretching rates compared to their nonionic parent polymer, thereby providing more environmentally friendly processing conditions for entangled ionomer melts.

\section{CONCLUSIONS}

We neutralized poly(styrene-co-4-vinylbenzoic acid) using relatively long-chain diamines to produce ionomers. The resulting ionomers showed lower $T_{\mathrm{g}}$ than their parent polymer, and $T_{\mathrm{g}}$ decreased with increasing diamine molar mass as a result of increasing chain mobility. In addition, these neutralized ionomers displayed a single transition in DSC traces and obey time-temperature superposition, indicating a 

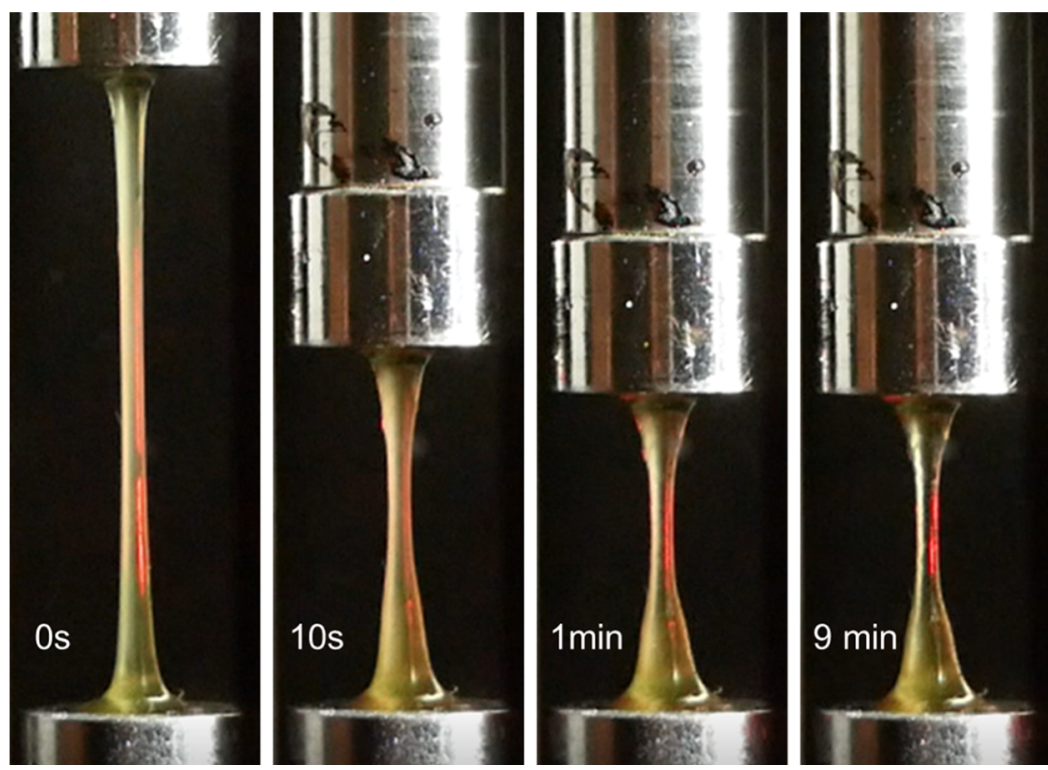

Figure 9. Stress relaxation at Hencky strain 2.8 of sample $\mathrm{PS}_{0.95} \mathrm{~A}_{0.05}+\mathrm{D} 2000$ stretched at $70{ }^{\circ} \mathrm{C}, 0.114 \mathrm{~s}^{-1}$ : from left to right, the photos correspond to $0 \mathrm{~s}, 10 \mathrm{~s}, 1 \mathrm{~min}$, and 9 min after stopping the stretching.
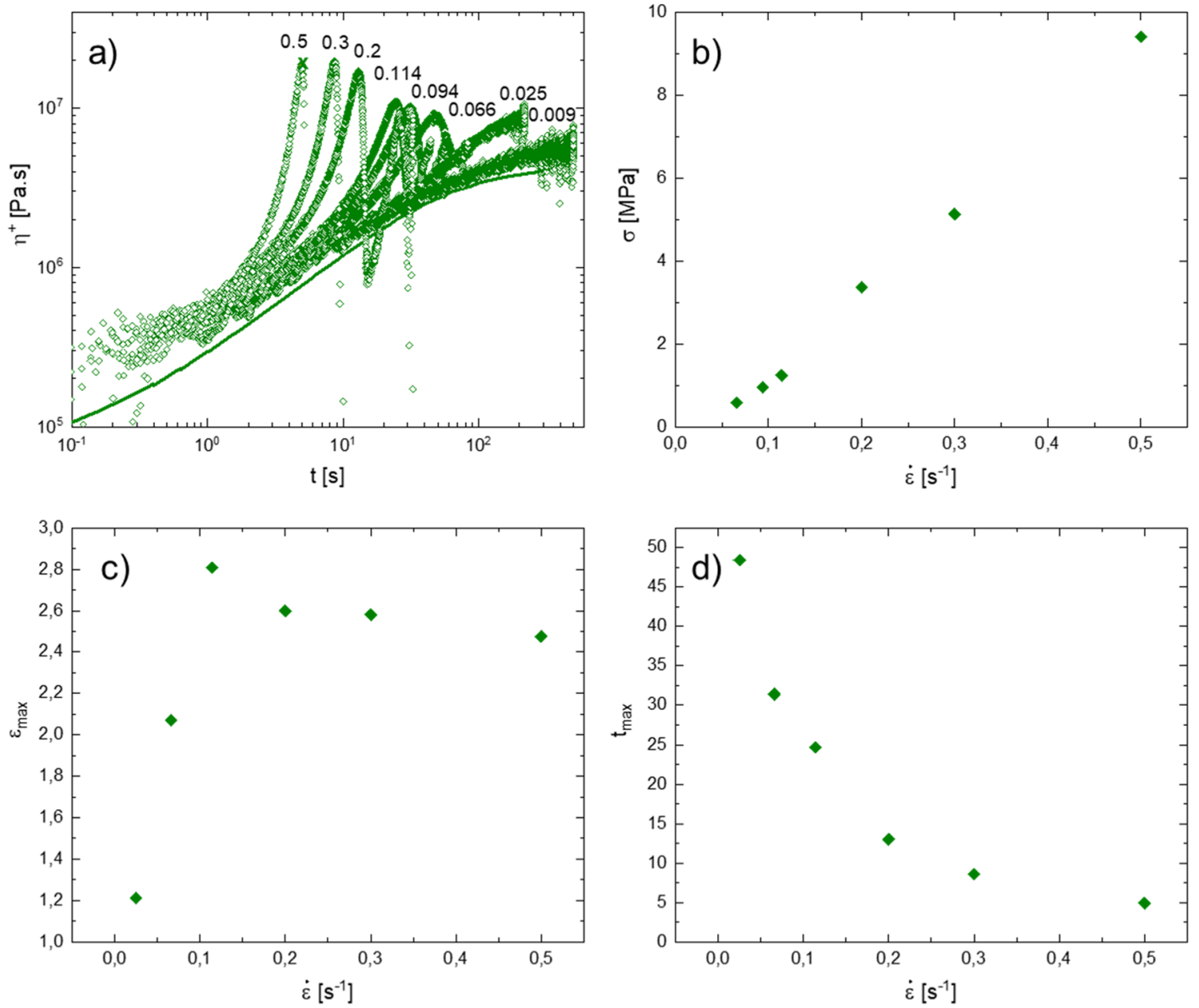

Figure 10. (a) Extensional stress growth coefficient as a function of time for $\mathrm{PS}_{0.95} \mathrm{~A}_{0.05}+\mathrm{D} 2000$ stretched at different rates. The stretch rates are indicated in the above figure $\left[\mathrm{s}^{-1}\right]$. (b) Maximum stress as a function of stretch rate. (c) Hencky strain, where the maximum stress locates $\left(\varepsilon_{\max }\right)$ as a function of stretch rate. (d) Time $([\mathrm{s}])$, where the maximum stress locates $\left(t_{\max }\right)$ as a function of stretch rate.

homogeneous material with ionic interaction acting as a compatibilizer. The relaxation time of the ionomer melts decreased with increasing diamine chain length, as confirmed via LVE measurements. Ionic cluster formation is prevented by 
the use of a low ion concentration as well as the use of ammonium as a counterion, which significantly enhances the entangled ionomers' flowability.

By investigating the nonlinear extensional properties of this entangled ionomer system, we successfully differentiated relaxation mechanisms due to entanglements from those due to ionic interactions, thereby providing guidance for future attempts to improve ionomer properties. The strain hardening behavior of the ionomers can be adjusted to match the parent molecule by using different diamines at a lower Weissenberg number than that of the parent polymer. Introducing stickers of different lengths thus provides the ability to tune the materials' degree of strain hardening. A stress maximum and overshoot appear in the stress-strain response and are related to sticker disassociation, as evidenced by the transition to opacity during filament stretching. After the maximum stress, the stickers tend to reassociate, resulting in a final steady stress similar to that of a PS solution. The sticker reorganization, together with the contributions from entanglements, enable excellent ionomer extensibility. This study provides a roadmap for the design of new easily processed, extensible ionomers with superior strain hardening.

\section{ASSOCIATED CONTENT}

\section{S1 Supporting Information}

The Supporting Information is available free of charge at https://pubs.acs.org/doi/10.1021/acs.macromol.0c02408.

${ }^{1} \mathrm{H}$ NMR spectra of Jeffamines; IR absorption spectra; normalized chromatograms; DSC traces; TGA; LVE master curves; strain hardening factor; extensional measurements; materials; and experimental procedures (PDF)

Filament stretching of sample $\mathrm{PS}_{0.95} \mathrm{~A}_{0.05}+\mathrm{D} 2000$ at $70^{\circ} \mathrm{C}, 0.114 \mathrm{~s}^{-1}$ (MP4)

Filament stretching of sample $\mathrm{PS}_{0.95} \mathrm{~A}_{0.05}+\mathrm{D} 2000$ at $70^{\circ} \mathrm{C}, 0.009 \mathrm{~s}^{-1}$ (MP4)

Filament stretching of sample PS77kD2000-69 at $110^{\circ} \mathrm{C}, 0.114 \mathrm{~s}^{-1}$ (MP4)

\section{AUTHOR INFORMATION}

\section{Corresponding Authors}

Anne L. Skov - Danish Polymer Center, Department of Chemical and Biochemical Engineering, Technical University of Denmark, 2800 Kgs. Lyngby, Denmark; (1) orcid.org/ 0000-0003-1223-6638; Email: al@kt.dtu.dk

Qian Huang - Danish Polymer Center, Department of Chemical and Biochemical Engineering, Technical University of Denmark, 2800 Kgs. Lyngby, Denmark; (이이.org/ 0000-0001-8777-4241; Email: qh@kt.dtu.dk

\section{Authors}

Wendi Wang - Danish Polymer Center, Department of Chemical and Biochemical Engineering, Technical University of Denmark, 2800 Kgs. Lyngby, Denmark; (ㅇ orcid.org/ 0000-0003-3357-7685

Jeppe Madsen - Danish Polymer Center, Department of Chemical and Biochemical Engineering, Technical University of Denmark, 2800 Kgs. Lyngby, Denmark; (1) orcid.org/ 0000-0001-7625-9498

Natalja Genina - Department of Pharmacy, University of Copenhagen, 2100 Copenhagen, Denmark
Ole Hassager - Danish Polymer Center, Department of Chemical and Biochemical Engineering, Technical University of Denmark, 2800 Kgs. Lyngby, Denmark; 이이.org/ 0000-0003-2695-6791

Complete contact information is available at: https://pubs.acs.org/10.1021/acs.macromol.0c02408

\section{Notes}

The authors declare no competing financial interest.

\section{ACKNOWLEDGMENTS}

The financial support from the European Union's Horizon 2020 Programme for Research and Innovation under the Marie Skłodowska-Curie grant agreement number 765811 (DoDyNet) is gratefully acknowledged.

\section{REFERENCES}

(1) Utracki, L. A.; Walsh, D. J.; Weiss, R. A. Polymer Alloys, Blends, and Ionomers. ACS Symp. Ser. 1989, 395, 1-35.

(2) Zhang, L.; Brostowitz, N. R.; Cavicchi, K. A.; Weiss, R. A. Perspective: Ionomer Research and Applications. Macromol. React. Eng. 2014, 8, 81-99.

(3) Hara, M.; Jar, P.; Sauer, J. A. Dynamic Mechanical Properties of Sulphonated Polystyrene Ionomers. Polymer 1991, 32, 1622-1626.

(4) Ma, X.; Sauer, J. A.; Hara, M. Poly(Methyl Methacrylate) Based Ionomers. 1. Dynamic Mechanical Properties and Morphology. Macromolecules 1995, 28, 3953-3962.

(5) Weiss, R. A.; Agarwal, P. K.; Lundberg, R. D. Control of Ionic Interactions in Sulfonated Polystyrene Ionomers by the Use of Alkylsubstituted Ammonium Counterions. J. Appl. Polym. Sci. 1984, 29, 2719-2734.

(6) Fan, X.-D.; Bazuin, C. G. Sulfonated Polystyrene Ionomers Neutralized by $\mathrm{Bi}-$ and Multifunctional Organic Cations. 2. Orientation and Dynamic Mechanical Study. Macromolecules 1995, $28,8216-8223$.

(7) Vanhoorne, P.; Register, R. A. Low-Shear Melt Rheology of Partially-Neutralized Ethylene-Methacrylic Acid Ionomers. Macromolecules 1996, 29, 598-604.

(8) Nishioka, A.; Takahashi, T.; Masubuchi, Y.; Takimoto, J.-i.; Koyama, K. Rheological Characterization of Ionic Bonding in Ethylene-Ionomer Melts with Low Neutralization Degree. J. Rheol. 2002, 46, 1325-1339.

(9) Weiss, R. A.; Fitzgerald, J. J.; Kim, D. Viscoelastic Behavior of Lightly Sulfonated Polystyrene Ionomers. Macromolecules 1991, 24, 1071-1076.

(10) Bazuin, C. G.; Eisenberg, A. Dynamic Mechanical Properties of Plasticized Polystyrene-based Ionomers. I. Glassy to Rubbery Zones. J. Polym. Sci., Part B: Polym. Phys. 1986, 24, 1137-1153.

(11) Nishida, M.; Eisenberg, A. Dynamic Mechanical Study of Sodium Sulfonated Random Ionomers Based on Hydrogenated Styrene-Butadiene Copolymer. Macromolecules 1996, 29, 1507-1515.

(12) Qiao, X.; Weiss, R. A. Nonlinear Rheology of Lightly Sulfonated Polystyrene Ionomers. Macromolecules 2013, 46, 24172424.

(13) Ling, G. H.; Wang, Y.; Weiss, R. A. Linear Viscoelastic and Uniaxial Extensional Rheology of Alkali Metal Neutralized Sulfonated Oligostyrene Ionomer Melts. Macromolecules 2012, 45, 481-490.

(14) Tierney, N. K.; Register, R. A. Ion Hopping in EthyleneMethacrylic Acid Ionomer Melts as Probed by Rheometry and Cation Diffusion Measurements. Macromolecules 2002, 35, 2358-2364.

(15) Shabbir, A.; Huang, Q.; Baeza, G. P.; Vlassopoulos, D.; Chen, Q.; Colby, R. H.; Alvarez, N. J.; Hassager, O. Nonlinear Shear and Uniaxial Extensional Rheology of Polyether-Ester-Sulfonate Copolymer Ionomer Melts. J. Rheol. 2017, 61, 1279-1289.

(16) Shabbir, A.; Huang, Q.; Chen, Q.; Colby, R. H.; Alvarez, N. J.; Hassager, O. Brittle Fracture in Associative Polymers: The Case of Ionomer Melts. Soft Matter 2016, 12, 7606-7612. 
(17) Chen, Q.; Zhang, Z.; Colby, R. H. Viscoelasticity of Entangled Random Polystyrene Ionomers. J. Rheol. 2016, 60, 1031-1040.

(18) Chen, Q.; Huang, C.; Weiss, R. A.; Colby, R. H. Viscoelasticity of Reversible Gelation for Ionomers. Macromolecules 2015, 48, 12211230.

(19) Zhang, Z.; Chen, Q.; Colby, R. H. Dynamics of Associative Polymers. Soft Matter 2018, 14, 2961-2977.

(20) Lundberg, R. D.; Duvdevani, I. Shear-Thickening Behavior of Ionomers and Their Complexes. ACS Symp. Ser. 1991, 462, 155-175.

(21) Witten, T. A.; Cohen, M. H. Cross-Linking in ShearThickening Ionomers. Macromolecules 1985, 18, 1915-1918.

(22) Huang, C.; Chen, Q.; Weiss, R. A. Nonlinear Rheology of Random Sulfonated Polystyrene Ionomers: The Role of the Sol-Gel Transition. Macromolecules 2016, 49, 9203-9214.

(23) Weiss, R. A.; Zhao, H. Rheological Behavior of Oligomeric Ionomers. J. Rheol. 2009, 53, 191-213.

(24) Wu, S.; Cao, X.; Zhang, Z.; Chen, Q.; Matsumiya, Y.; Watanabe, H. Molecular Design of Highly Stretchable Ionomers. Macromolecules 2018, 51, 4735-4746.

(25) Stadler, F. J.; Still, T.; Fytas, G.; Bailly, C. Elongational Rheology and Brillouin Light Scattering of Entangled Telechelic Polybutadiene Based Temporary Networks. Macromolecules 2010, 43, 7771-7778.

(26) Connelly, R. W.; McConkey, R. C.; Noonan, J. M.; Pearson, G. H. Melt Rheology of Ion-Containing Polymers. 1. Effect of Ionic Content in a Model Polyesterionomer. J. Polym. Sci., Part A-2 1982, 20, 259-268.

(27) Kim, J.-S.; Yoshikawa, K.; Eisenberg, A. Molecular Weight Dependence of the Viscoelastic Properties of Polystyrene-Based Ionomers. Macromolecules 1994, 27, 6347-6357.

(28) Huang, Q.; Hassager, O. Polymer Liquids Fracture like Solids. Soft Matter 2017, 13, 3470-3474.

(29) Zhang, L.; Katzenmeyer, B. C.; Cavicchi, K. A.; Weiss, R. A.; Wesdemiotis, C. Sulfonation Distribution in Sulfonated Polystyrene Ionomers Measured by MALDI-ToF MS. ACS Macro Lett. 2013, 2, 217-221.

(30) Ndoni, S.; Papadakis, C. M.; Bates, F. S.; Almdal, K. Laboratory-Scale Setup for Anionic Polymerization under Inert Atmosphere. Rev. Sci. Instrum. 1995, 66, 1090-1095.

(31) Nagaki, A.; Tsuchihashi, Y.; Haraki, S.; Yoshida, J.-i. Benzyllithiums Bearing Aldehyde Carbonyl Groups. A Flash Chemistry Approach. Org. Biomol. Chem. 2015, 13, 7140-7145.

(32) Wang, W.; Madsen, J.; Skov, A. L.; Huang, Q. Improvement of Mechanical Properties of Anisotropic Glassy Polystyrene by Introducing Heat-Labile Reversible Bonds. Macromolecules 2019, 52, 9261-9271.

(33) Bach, A.; Almdal, K.; Rasmussen, H. K.; Hassager, O. Elongational Viscosity of Narrow Molar Mass Distribution Polystyrene. Macromolecules 2003, 36, 5174-5179.

(34) Huang, Q.; Mednova, O.; Rasmussen, H. K.; Alvarez, N. J.; Skov, A. L.; Almdal, K.; Hassager, O. Concentrated Polymer Solutions Are Different from Melts: Role of Entanglement Molecular Weight. Macromolecules 2013, 46, 5026-5035.

(35) Rasmussen, H. K.; Bejenariu, A. G.; Hassager, O.; Auhl, D. Experimental Evaluation of the Pure Configurational Stress Assumption in the Flow Dynamics of Entangled Polymer Melts. J. Rheol. 2010, 54, 1325-1336.

(36) Yang, G.; Fu, S.-Y.; Yang, J.-P. Preparation and Mechanical Properties of Modified Epoxy Resins with Flexible Diamines. Polymer 2007, 48, 302-310.

(37) Tudryn, G. J.; Liu, W.; Wang, S.-W.; Colby, R. H. Counterion Dynamics in Polyester - Sulfonate Ionomers with Ionic Liquid Counterions. Macromolecules 2011, 44, 3572-3582.

(38) Eisenbach, C. D.; Hofmann, J.; Macknight, W. J. Dynamic Mechanical and Spectroscopic Study of Ionomer Blends Based on Carboxylated or Sulfonated Flexible Polystyrene and Rigid Poly (Diacetylenes) with Functional Side Groups. Macromolecules 1994, $27,3162-3165$.
(39) Weiss, R. A.; Beretta, C.; Sasongko, S.; Garton, A. Miscibility Enhancement of Polystyrene and Poly (Alkylene Oxide) Blends Using Specific Intermolecular Interactions. J. Appl. Polym. Sci. 1990, 41, 91103.

(40) Cai, H.; Ait-Kadi, A.; Brisson, J. Dynamic Rheological Analysis of a Miscible Blend Showing Strong Interactions. Polymer 2003, 44, 1481-1489.

(41) Yang, Z.; Han, C. D. Rheology of Miscible Polymer Blends with Hydrogen Bonding. Macromolecules 2008, 41, 2104-2118.

(42) Chen, Q.; Tudryn, G. J.; Colby, R. H. Ionomer Dynamics and the Sticky Rouse Model. J. Rheol. 2013, 57, 1441-1462.

(43) Chen, Q.; Liang, S.; Shiau, H.-s.; Colby, R. H. Linear Viscoelastic and Dielectric Properties of Phosphonium Siloxane Ionomers. ACS Macro Lett. 2013, 2, 970-974.

(44) Chen, Q.; Zhang, Z.; Colby, R. H.; Colby, R. H. Viscoelasticity of Entangled Random Polystyrene Ionomers. J. Rheol. 2016, 60, 1031-1040. 